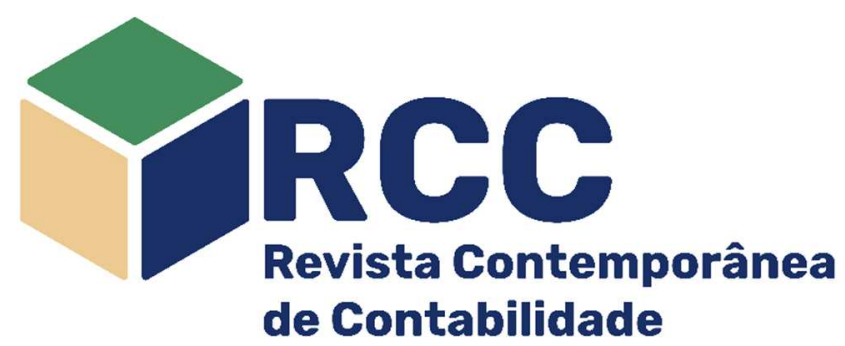

\title{
Compras públicas para enfrentamento da Covid-19: uma análise sob a lente da teoria contingencial
}

\author{
Public procurement to confront COVID-19: an analysis based on the contingency theory
Contratación pública para hacer frente al Covid-19: un análisis desde la lente de la teoría de la contingencia

\author{
Saulo Silva Lima Filho* \\ Mestre em Contabilidade (UFPR) \\ Diretor de Contabilidade e Finanças da Universidade \\ Federal do Paraná (UFPR), Curitiba/PR, Brasil \\ sslf87@hotmail.com \\ https://orcid.org/0000-0003-2199-8386 (1)
}

\author{
Gislene Daiana Martins \\ Mestre em Contabilidade (UFPR) \\ Professora Substituta do Departamento de Ciências Contábeis, \\ Campus Pato Branco (UTFPR), Pato Branco/PR, Brasil \\ gislenedaiana@gmail.com \\ https://orcid.org/0000-0003-0871-6778 (]) \\ Blênio Cezar Severo Peixe \\ Doutor em Engenharia de Produção (UFSC) \\ Professor Associado da Universidade Federal do Paraná (UFPR), \\ Curitiba/PR, Brasil \\ bleniocsp@gmail.com \\ https://orcid.org/0000-0001-8271-0628 (1)
}

Endereço do contato principal para correspondência* Av. Prefeito Lotário Meissner, 632 - Campus III, Jardim Botânico, CEP: 80210-170 - Curitiba/PR, Brasil

\section{Resumo}

A partir da teoria contingencial, este estudo analisa as características das aquisições públicas por dispensa de licitação para enfrentar a Covid-19. Assumindo que as incertezas relacionadas ao ambiente externo alteram a dinâmica das aquisições, abordaram-se as despesas empenhadas no Governo Federal durante 2020. Os dados compilados permitiram comparar as características das dispensas de licitação realizadas sob amparo da Lei 8.666/1993 e aquelas originadas da Lei 13.979/2020, específica para combater a pandemia. Utilizaram-se análises descritivas e teste chi-quadrado para verificar a associação entre as características e criar mapas perceptuais mediante análise de correspondência múltipla. Os resultados demonstram que, apesar da diferença entre os objetivos institucionais de cada órgão, há sintonia na aplicação dos recursos em relação à Covid-19. O custo dessas aquisições é elevado em razão do afrouxamento de limites gerado pela Lei 13.979/2020, denotando que as incertezas do ambiente externo são fundamentais para modificar pautas e alinhar os objetivos das instituições.

Palavras-chave: COVID-19; Teoria Contingencial; Classificações Orçamentárias e Licitatórias; Aquisições Públicas

\section{Abstract}

This study analyzes the characteristics of public acquisitions by exemption from bidding to face COVID-19 from the perspective of Contingency Theory. By assuming that the uncertainties related to the external environment alter the dynamics of acquisitions, expenditures committed to the federal government during the entire fiscal year 2020 were analyzed. The compiled data compare the characteristics of the bidding exemptions applied under the traditional protection of Law 8,666/1993 to those that originated from Law $13,979 / 2020$, specific to face the pandemic. The study used descriptive analyzes, Chi-Square test, to verify the association between the characteristics and created perceptual maps with the aid of Multiple Correspondence Analysis. The results show that, despite the difference among the institutional objectives of each body, there is a harmony in the application of resources when the theme is COVID-19. The cost of procurements related to COVID-19 is high due to the loosening of limits by Law 13,979/2020, showing that the uncertainties of the external environment are essential to modify the guidelines of the institutions and align their objectives. 
Keywords: COVID-19; Contingency Theory; Budgetary and Bid Classifications; Public Procurement

\section{Resumen}

El estudio analiza las características de las adquisiciones públicas por exención de licitación para enfrentar el Covid-19 desde la perspectiva de la Teoría de Contingencias. Suponiendo que las incertidumbres relacionadas con el entorno externo alteran la dinámica de adquisiciones, se analizaron los gastos comprometidos con el gobierno federal durante todo el año fiscal 2020. Los datos recopilados comparan las características de las exenciones de licitación realizadas al amparo de la tradicional protección de la Ley $8.666 / 1993$ a las que se originaron en la Ley 13.979/2020, específica para combatir la pandemia. La investigación utiliza análisis descriptivos, prueba de Chi-Cuadrado, para verificar la asociación entre las características y mapas perceptivos creados a través del Análisis de Correspondencia Múltiple. Los resultados demuestran que, a pesar de la diferencia entre los objetivos institucionales de cada organismo, existe una armonía en la aplicación de los recursos cuando el tema es Covid-19. El costo de adquisiciones relacionadas con Covid-19 es alto, debido a la flexibilización de límites por la Ley 13.979/2020, mostrando que las incertidumbres del entorno externo son fundamentales para modificar los lineamientos de las instituciones y alinear sus objetivos.

Palabras clave: COVID-19; Teoria de la Contingencia; Clasificaciones Presupuestarias y de Licitaciones; La Contratación Pública

\section{Introdução}

Nos últimos anos o desempenho do setor público ganhou relevância por sua capacidade de fornecer serviços com recursos públicos de forma eficiente, eficaz e efetiva, questões que preocupam tanto quem formula essas políticas quanto os analistas (Andrews et al., 2016). Todavia, estudos recentes demonstram como o ambiente externo impõe desafios às instituições, fenômeno comumente abordado pela teoria da contingência, que indica quais fatores podem influenciar o comportamento e a capacidade das organizações de tomar decisões (Donaldson, 2001).

Os fatores organizacionais internos podem ser ajustados ou adaptados de acordo com as necessidades e objetivos identificados, de modo que a teoria da contingência sugere que os resultados das organizações são amplamente moldados por seu contexto externo e interno (Andrews et al., 2016). Logo, os fatores ambientais influenciam a dinâmica das negociações, afetando a riqueza de empresas privadas e públicas e gerando desafios e ameaças em suas operações e no ambiente econômico de forma geral (Klann et al., 2014).

Em relação ao atual cenário de pandemia, é necessário debater a influência do ambiente externo na aplicação dos recursos destinados a combater a Covid-19. Para isso são comparadas dispensas de licitações que envolvem tanto aquisições comuns, referenciadas pela Lei 8.666/1993 (Lei 8.666, 1993), quanto as que decorrem de um fator extremo como a pandemia e recebem amparo da Lei 13.979/2020 (Lei 13.979, 2020). Desse contexto surge a pergunta que motiva esta pesquisa: quais as características das aquisições públicas feitas por meio de dispensa de licitação para enfrentar a pandemia de Covid-19? Nesse sentido, na atual conjuntura de pandemia e recessão econômica, analisar o comportamento das despesas por meio das características das aquisições públicas faz emergir sua importância acadêmica e, sobretudo, econômica e social, tendo em vista o impacto sobre a economia do país - para atender uma demanda social por saúde pública de caráter contingencial - gerado pela alocação de recursos (que deveriam ser destinados a outras áreas) para aquisições de enfrentamento à pandemia.

Do ponto de vista prático, esta pesquisa verifica se as aquisições para enfrentar a pandemia têm características notadamente distintas das compras tradicionais. Além disso, é possível observar o direcionamento dos recursos públicos, seja por aspectos institucionais, seja por elementos funcionaisprogramáticos. Uma das contribuições teóricas que se destaca neste estudo é a aplicação da teoria contingencial a entidades do setor público, evidenciando uma lacuna nas pesquisas, visto que não foram encontrados estudos relacionando o comportamento das despesas públicas à teoria contingencial.

Da perspectiva acadêmica, é relevante que sejam realizados estudos, inclusive interdisciplinares, que lancem luz e permitam compreender essa doença até então desconhecida, cujos reflexos na saúde, na vida em sociedade e nas condições econômicas ainda são desconhecidos. Nesse sentido, este estudo preenche uma lacuna nas pesquisas ao investigar como a atuação governamental tem se comportado neste momento ímpar, especialmente quanto aos esforços para agilizar e flexibilizar as compras de itens pertinentes à pandemia de Covid-19.

\section{Referencial Teórico}

Neste referencial teórico foram conceituados aspectos relacionados à teoria contingencial de forma geral, classificações orçamentárias e licitatórias. 


\subsection{Teoria contingencial}

A teoria contingencial parte da premissa de que fatores contingenciais afetam a dinâmica das organizações. O estudo basilar sobre essa teoria foi feito por Burns e Stalker (1961), no qual os autores examinaram como as organizações identificam e respondem às condições de estabilidade e mudança geradas pelo ambiente interno e externo, classificando as respostas em apropriadas ou disfuncionais. Em outras palavras, eles buscaram verificar a relação entre o ambiente interno (as práticas gerenciais) e o externo dessas organizações.

Espejo (2008) sintetiza as estruturas mecanicistas de Burns e Stalker (1961), segundo as quais o controle é concentrado, há maior rigidez hierárquica e maior especialização das tarefas, bem como hierarquização (estruturas mais verticalizadas), além da centralização e formalização dos controles. $\mathrm{Na}$ estrutura orgânica, por sua vez, há menor rigidez em relação à hierarquia, que é mais horizontalizada, delegam-se mais as tarefas, os controles de gestão são mais informais é há menos especialização, visto que não se prioriza a divisão social do trabalho, conforme mencionado anteriormente.

A abordagem contingencial está relacionada ao ambiente e a sua interdependência em relação às práticas gerenciais voltadas para a tomada de decisão dos gestores. Essa relação é altamente complexa, pois envolve múltiplos fatores. Dessa forma, percebe-se que a variável ambiente é independente, ao contrário das práticas gerenciais. Logo, a abordagem contingencial gera um comportamento reativo nas organizações, isto é, o ambiente influencia as práticas gerenciais (Espejo, 2008).

De maneira geral, o cerne da teoria contingencial é que as organizações, públicas ou privadas, são afetadas por fatores contingenciais externos ou internos. Otley (2016) menciona que os fatores externos incluem tecnologia, competição ou hostilidade no mercado, incerteza ambiental e cultura nacional (Sell., Beuren \& Lavarda, 2020).

Chenhall (2003) atenta para a importância do ambiente externo no processo decisório. Para ele, o ambiente externo é uma poderosa variável contextual que está na base da pesquisa fundamentada em contingências, sobretudo em função da incerteza que permeia essa variável. Segundo Wadongo e AbdelKader (2014), o ambiente é um fator contingencial relevante por causa da incerteza ou dificuldade de previsão, dinamismo e adversidades enfrentadas pelas organizações.

Tendo em vista que a teoria da contingência procura compreender e explicar o modo pelo qual as empresas funcionam em diferentes condições, que variam de acordo com o ambiente em que elas estão inseridas e que são influenciadas conforme seu ambiente externo, aceita-se, portanto, que ameaças ou oportunidades influenciam a estrutura e os processos internos das organizações (Beuren \& Fiorentin, 2014). Diante disso, torna-se relevante analisar o comportamento das despesas públicas no atual contexto de incertezas causado pela Covid-19.

\subsubsection{Teoria contingencial no setor público}

Christensen e Yoshimi (2003) verificaram o papel dos órgãos profissionais em estimular mudanças, em especial quanto às variáveis estruturais, para explicar as alterações contábeis do setor público, apontando a necessidade de pesquisar a influência das empresas de consultoria de gestão como fator para compreender os relatórios de desempenho alterados.

Andrews et al. (2016) utilizaram a teoria contingencial e a teoria baseada em recursos para analisar a capacidade organizacional no setor público. Suas descobertas identificam uma única configuração central dos atributos organizacionais associados aos departamentos de alta capacidade e de baixa complexidade estrutural e estabilidade do pessoal. Por sua vez, Costa Netto (2017) pesquisou a governança de tecnologia da informação (GTI) em uma organização pública do Rio Grande do Sul, analisando como os fatores contingenciais podem alterar o balanço de poder entre as subunidades de uma organização. $O$ autor adotou a teoria das contingências e estratégias do poder intraorganizacional de Hickson, Hinings, Lee, Schneck e Pennings (1971) com o objetivo geral de analisar a influência do poder intraorganizacional na efetividade do mecanismo de GTI.

Cavichioli et al. (2018) analisaram como os fatores contingenciais influenciam a implantação dos subsistemas de informação de custos no setor público (Sicsp), buscando acrescentar resultados à teoria contingencial. Por sua vez, Sell et al. (2020) investigaram a influência de fatores contingenciais no desempenho de municípios ao longo de três mandatos governamentais. Considerando elementos contingenciais internos, os autores revelaram sua influência significativa no desempenho dos municípios.

De maneira geral, observa-se que os fatores contingenciais, internos ou externos à organização, influenciam a dinâmica organizacional no ambiente público, bem como evidenciam as informações que podem ser alteradas pela influência deles. Nesse sentido, os fatores contingenciais têm grande probabilidade de alterar o comportamento das despesas no setor público, sobretudo em relação ao atual cenário de contingenciamento dos recursos públicos causado pela Covid-19. Dessa forma, é necessário avaliar se as despesas estão sendo alocadas conforme previsto para o enfrentamento da pandemia. 


\subsection{Classificações orçamentárias e licitatórias}

A classificação orçamentária permite que o ente governamental padronize e direcione sua atuação de acordo com suas finalidades, prezando pelas ações institucionais esperadas e previstas nas normas de planejamento público. Para tanto, os recursos orçamentários são dispostos de acordo com programas, subprogramas e demais delineamentos para atingir os objetivos institucionais (Ibrahim, 2011). Esse processo de segmentação das funções e dos programas entre os órgãos é fundamental para o processo político, administrativo e econômico de atuação do governo, indicando os objetivos institucionais e as áreas e objetivos dos gastos de recursos (Cretu, 2013).

Assim, a administração pública, utilizando as classificações funcional-programática, institucional e da natureza das despesas, poderá detalhar seus planos de ação e agir de maneira a incrementar, reduzir ou mesmo alterar os direcionamentos organizacionais (Mikesell \& Mullins, 2001), como no caso das compras para enfrentar a pandemia da Covid-19, quando órgãos públicos com objetivos institucionais e funcionaisprogramáticos se adaptaram ao ambiente e direcionaram suas aquisições a objetos comuns.

Nessa seara, a classificação orçamentária, avaliada em critérios funcionais-programáticos, é tida como uma modernização inerente ao orçamento-programa, haja vista que demonstra as realizações e o esforço governamental em benefício da população. Além disso, o delineamento mediante a natureza das despesas aponta os meios pelos quais o governo intervém na sociedade, promovendo investimentos públicos e formação de patrimônio. Esse delineamento também pode ocorrer de modo puramente analítico, na forma de elementos de despesa, que expõem estritamente a que se refere o gasto (Giacomoni, 2019).

Outra maneira de avaliar os dispêndios públicos aborda a forma como as aquisições foram realizadas. Para tanto, diversos procedimentos formais são instaurados buscando, dentre outros, auferir impessoalidade, isonomia, publicidade e competição entre os participantes interessados em fornecer materiais e serviços ao governo (Lima, 2018). Contudo, é preciso salientar que o trâmite licitatório é considerado engessado e burocrático, por vezes inviabilizando aquisições tempestivas de maneira dinâmica (Vieira et al., 2018).

Dito isso, para tornar mais ágil e flexível o processo de aquisição, foram criadas modalidades de licitação específicas, que distinguem os trâmites e formalidades de acordo com o tipo de compra e valor. Nessa seara surge a dispensa de licitação, prevista pelo artigo 24 da Lei 8.666/1993 (Lei 8.666, 1993), que abriga compras alheias a obras e serviços de engenharia de até $R \$ 17.600,00$ (dezessete mil e seiscentos reais), conforme o Decreto 9.412/2018. Cabe frisar que essa excepcionalidade só é aplicável em situações pontuais, previstas pela própria lei de licitações, sobretudo quando a competição entre fornecedores é inviável (Lima, 2018; Trilha et al., 2018).

Percebe-se ainda que, embora a dispensa de licitação permita uma contratação mais simplificada, em um momento de calamidade pública de saúde, como o vivenciado com a Covid-19, os procedimentos precisavam ser ainda mais flexíveis, acolhendo aquisições tempestivas de acordo com a necessidade de cada órgão. Nesse contexto, foi promulgada a Lei 13.979/2020 (Lei 13.979, 2020), dispondo sobre medidas para enfrentar a pandemia, dentre as quais, regras específicas para aquisições que permitem utilizar a dispensa de licitação em compras para combater o coronavírus, além da instrução processual simplificada que acelera o processo de contratação.

\section{Aspectos Metodológicos}

Este é um estudo descritivo e explicativo, que utiliza uma abordagem quantitativa a partir das estatísticas descritivas e da análise de correspondência múltipla. Para tanto, considerando o objetivo proposto, foram levantados dados sobre as características das aquisições públicas do governo federal durante todo o exercício de 2020, período em que a pandemia se alastrou em território nacional. Nesse sentido, foi construída uma base contendo dados categóricos sobre a classificação orçamentária e licitatória das aquisições públicas durante o ano.

Tais dados foram coletados na plataforma Sistema Tesouro Gerencial (STG, 2020), que compila registros do Sistema Integrado de Administração Financeira do Governo Federal, permitindo distinguir os embasamentos legais utilizados nas compras para combater o coronavírus das demais despesas recorrentes. É preciso frisar que os dados agregados no sistema estão disponíveis no portal da transparência (Controladoria Geral da União, 2021). Entretanto, com o auxílio da plataforma, foi possível criar filtros de acordo com as despesas empenhadas, discriminando os órgãos envolvidos e dispondo os dados de acordo com sua classificação funcional-programática, licitatória e por meio da natureza da despesa.

Acerca da categorização da amostra, do ponto de vista licitatório houve uma concentração nas aquisições públicas realizadas mediante dispensa de licitação. Nesse sentido, foram comparadas as compras que utilizaram como referência a Lei 8.666/1993 (Lei 8.666, 1993) com aquelas que se basearam na possibilidade de aquisição simplificada por meio da Lei 13.979/2020 (Lei 13.979, 2020), exclusiva para enfrentamento da pandemia.

A opção pelas dispensas de licitação ocorre em razão das condições de aquisição, que destoam dos demais instrumentos licitatórios previstos nas normas aplicáveis, simplificando o certame em virtude da possibilidade de compra mediante valores irrisórios sem prejudicar a imparcialidade na adjudicação do 
fornecedor (Giacomoni, 2019).

Ademais, a escolha pelas dispensas de licitação considera que poderia haver divergências de comparabilidade entre instrumentos licitatórios distintos para enfrentar a pandemia, especialmente porque a Lei 13.979/2020 (Lei 13.979, 2020) previu apenas uma nova forma de aquisição mediante dispensa, sem intervir nos demais dispositivos. Diante disso, para manter a isonomia na comparação, neste estudo foram classificadas as aquisições entre dispensas previstas pela Lei 13.979/2020 (Lei 13.979, 2020) e pela Lei 8.666/1993 (Lei 8.666, 1993).

Quanto às categorizações orçamentárias, as variáveis foram classificadas de acordo com sua função programática, a natureza das despesas e o ramo da instituição. A partir desses dados é possível identificar as ações institucionais, objetos de aplicação dos recursos e a finalidade de atuação do órgão (Giacomoni, 2019; Lima, 2018; Ministério da Fazenda, 2019).

Dito isso, cabe salientar que o orçamento inicial previsto pela Lei Orçamentária não pressupunha ações específicas para enfrentar a pandemia. Assim, durante o decorrer do exercício de 2020, foram adicionados recursos orçamentários específicos com essa finalidade, sobretudo com a criação da ação $21 \mathrm{C} 0$, que visou lidar com a emergência de saúde pública de importância internacional decorrente do coronavírus (Controladoria Geral da União, 2021). Além destes aspectos, foi apresentada a descrição das variáveis e dos procedimentos realizados para atender a questão de pesquisa por meio dos protocolos da análise estatística.

\subsection{Descrição das variáveis}

Foram utilizados conceitos relativos à classificação orçamentária, contendo 6 variáveis e outras duas variáveis licitatórias, além de categorizar em que tipo de órgão que executou a despesa, o que permite analisar pontualmente eventuais diferenças nos dispêndios entre diferentes órgãos ministeriais. Isto é, se os gastos se concentram em determinado órgão ou tem sido feito um esforço conjunto. A partir dessas considerações, por meio da Tabela 1, são demonstradas as variáveis utilizadas.

Tabela 1:

Construção das Variáveis

\begin{tabular}{|c|c|c|c|c|}
\hline $\begin{array}{l}\text { Variável } \\
\text { Observável }\end{array}$ & Categorização & $\begin{array}{c}\text { Conceito } \\
\text { Relacionado }\end{array}$ & Funcionamento & $\begin{array}{l}\text { Referencial } \\
\text { Teórico }\end{array}$ \\
\hline Amparo Legal & Covid-19, Demais Dispensas & Licitatório & $\begin{array}{c}\text { Segmenta as compras pelo fundamento legal, } \\
\text { seja pela Lei } 8666 / 93 \text { (compras regulares) ou } \\
\text { pela Lei } 13.979 / 20 \text { (Combate ao Covid-19) }\end{array}$ & $\begin{array}{c}\text { Vieira, } \\
\text { Andrade e } \\
\text { Ferreira (2018) } \\
\end{array}$ \\
\hline Institucional & $\begin{array}{c}\text { Contro/Administr } \\
\text { Legislativo } \\
\text { Judiciário } \\
\text { Out. Ministérios } \\
\text { Educação } \\
\text { Saúde } \\
\end{array}$ & Institucional & $\begin{array}{c}\text { Corresponde à atividade finalística ministerial } \\
\text { ou órgão máximo em que a despesa foi } \\
\text { realizada }\end{array}$ & $\begin{array}{c}\text { Mikesell e } \\
\text { Mullin (2001); } \\
\text { Giacomoni } \\
\text { (2019) }\end{array}$ \\
\hline Fonte de Recursos & $\begin{array}{c}\text { Tesouro } \\
\text { Transferências } \\
\text { Contribuições } \\
\text { Outras Receitas } \\
\text { Operações de Crédito } \\
\text { Rec. Próprios } \\
\text { Taxas } \\
\end{array}$ & Orçamentário & $\begin{array}{c}\text { Identifica as fontes de recursos que financiam } \\
\text { as atividades governamentais }\end{array}$ & MCASP (2019) \\
\hline $\begin{array}{l}\text { Programa } \\
\text { Orçamentário }\end{array}$ & $\begin{array}{l}\text { Outra Programação } \\
\text { Educação } \\
\text { Economia/Desenvol } \\
\text { Saúde } \\
\text { Segurança }\end{array}$ & $\begin{array}{l}\text { Orçamentário } \\
\text { Funcional- } \\
\text { Programática }\end{array}$ & $\begin{array}{c}\text { Articula o conjunto de ações para a } \\
\text { concretização de um objetivo comum } \\
\text { preestabelecido }\end{array}$ & $\begin{array}{l}\text { Lima (2018); } \\
\text { Giacomoni } \\
\text { (2019) }\end{array}$ \\
\hline $\begin{array}{l}\text { Função } \\
\text { Orçamentária }\end{array}$ & $\begin{array}{c}\text { Outra Func } \\
\text { Previdência } \\
\text { Educação } \\
\text { Segurança Pública } \\
\text { Agricultura } \\
\text { Economia/Desenvol } \\
\text { Cultura } \\
\text { Habitação } \\
\text { Saúde }\end{array}$ & $\begin{array}{l}\text { Orçamentário } \\
\text { Funcional- } \\
\text { Programática }\end{array}$ & $\begin{array}{l}\text { Relacionado com a missão institucional do } \\
\text { órgão com as áreas de atuação (saúde, } \\
\text { educação, segurança, dentre outros) }\end{array}$ & $\begin{array}{l}\text { Lima (2018); } \\
\text { Giacomoni } \\
\text { (2019) }\end{array}$ \\
\hline $\begin{array}{l}\text { Categoria } \\
\text { Econômica }\end{array}$ & Capital, Custeio & $\begin{array}{l}\text { Orçamentário } \\
\text { Natureza de } \\
\text { Despesa }\end{array}$ & $\begin{array}{c}\text { Permite reconhecer se a despesa está voltada } \\
\text { para formação de patrimônio (capital), ou se } \\
\text { trata de gastos correntes (custeio) }\end{array}$ & $\begin{array}{l}\text { Lima (2018); } \\
\text { Giacomoni } \\
(2019)\end{array}$ \\
\hline $\begin{array}{l}\text { Elemento de } \\
\text { Despesa }\end{array}$ & $\begin{array}{c}\text { Pessoal } \\
\text { Bolsas/Diárias } \\
\text { Despesa Fin. } \\
\text { Mat.Consum } \\
\text { Outros Elementos } \\
\text { Serviços Terc. } \\
\text { Obras e Imob } \\
\text { Material Perman }\end{array}$ & $\begin{array}{l}\text { Orçamentário } \\
\text { Natureza de } \\
\text { Despesa }\end{array}$ & $\begin{array}{c}\text { Identifica o objeto de gasto das despesas } \\
\text { públicas. Sua discriminação ocorre por meio de } \\
\text { subelementos }\end{array}$ & $\begin{array}{l}\text { Lima (2018); } \\
\text { Giacomoni } \\
\quad(2019)\end{array}$ \\
\hline
\end{tabular}




\begin{tabular}{c|c|c|c|c}
\hline $\begin{array}{c}\text { Variável } \\
\text { Observável }\end{array}$ & Categorização & $\begin{array}{c}\text { Conceito } \\
\text { Relacionado }\end{array}$ & Funcionamento & $\begin{array}{c}\text { Referencial } \\
\text { Teórico }\end{array}$ \\
\hline Valor Envolvido & Valor Vultoso, Valor Irrisório & Orçamentário & $\begin{array}{c}\text { Interpreta o Inciso II, Artigo 24 da Lei 8.666/93 } \\
\text { para determinar se o volume de despesas } \\
\text { incorridos é volumoso ou irrisório }\end{array}$ & $\begin{array}{c}\text { Vieira, Andrade } \\
\text { e Ferreira } \\
(2018) ; \\
\text { Giacomoni } \\
(2019)\end{array}$ \\
\hline
\end{tabular}

Nota: TIC: Equipamentos de Tecnologia da Informação e Comunicação

Fonte: Elaborado pelos autores

Cumpre esclarecer que todos os dados envolvidos são categóricos, de modo que, mediante essa classificação, é possível identificar características exclusivas das aquisições públicas por meio de dispensa de licitação para enfrentar a pandemia da Covid-19. Nesse sentido, o objeto de estudo são as características de realização das compras e não os valores envolvidos de modo soberano. Isso ocorre pois, independentemente do valor, a despesa pública precisa ser analisada e os controles públicos devem ser sensíveis, inclusive a pequenos valores realizados em grandes quantidades.

\subsection{Descrição dos procedimentos realizados}

Após coletar os dados e construir sua base, foi definido o seguinte protocolo de análise visando atender à questão de pesquisa na Tabela 2.

Tabela 2:

Protocolo de Análise

\begin{tabular}{|c|c|c|c|}
\hline $\begin{array}{l}\text { Técnica } \\
\text { Utilizada }\end{array}$ & Objetivo & Procedimento Envolvido & Suporte Teórico \\
\hline \multirow{2}{*}{$\begin{array}{l}\text { Estatísticas } \\
\text { Descritivas }\end{array}$} & $\begin{array}{c}\text { Criar tabelas de contingências que exibam as } \\
\text { frequências de ocorrência envolvendo aquisições } \\
\text { sob a Lei } 13.979 / 20 \text { e demais licitações. }\end{array}$ & $\begin{array}{l}\text { Distribuição de frequências } \\
\text { mediante tabelas de } \\
\text { contingências }\end{array}$ & \multirow{2}{*}{ Fávero e Belfiore (2017) } \\
\hline & $\begin{array}{l}\text { Verificar a associação entre o amparo legal e as } \\
\text { características institucional, orçamentário, funcional- } \\
\text { programática e licitatória. }\end{array}$ & Teste Chi-Quadrado $\left(X^{2}\right)^{1}$ & \\
\hline \multirow{3}{*}{$\mathrm{ACM}^{2}$} & \multirow{3}{*}{$\begin{array}{c}\text { Analisar a relação de interdependência entre o } \\
\text { amparo legal e as características das compras } \\
\text { públicas para enfrentamento da pandemia da Covid- } \\
19 .\end{array}$} & Autovalores & \multirow{3}{*}{$\begin{array}{l}\text { Wickham (2007); Le, Josse e } \\
\text { Husson (2008); Hair et al. (2009); } \\
\text { Kassambara e Mundt (2020). }\end{array}$} \\
\hline & & Correlação entre dimensões & \\
\hline & & $\begin{array}{l}\text { Distribuição gráficas de } \\
\text { categorias }\end{array}$ & \\
\hline
\end{tabular}

Nota: ${ }^{1}$ Significância ao nível de $0,1^{*} 0,05^{* *} 0,001^{* * *} ;{ }^{2} \mathrm{ACM}$ - Análise de Correspondência Múltipla

Fonte: Elaborado pelos Autores

Portanto, considerando os procedimentos da Tabela 2, os dados serão analisados por meio de estatísticas descritivas, visando conhecer o comportamento da amostra, bem como esclarecer, de maneira inicial, possíveis características das aquisições para combater a Covid-19. Além disso, foram verificadas diferenças significativas entre os grupos mediante uso do teste de chi-quadrado para, por fim, discorrer sobre a distribuição gráfica entre as categorias por meio de uma análise de correspondência múltipla (ACM), construindo uma estrutura que estabelece os perfis das observações e as relaciona com as variáveis analisadas. Os testes foram realizados com o auxílio do software estatístico $R$, versão 4.0.3 (R Foundation, 2010).

\section{Análise e Discussão dos Resultados}

Apresenta-se nesta seção as estatísticas descritivas e análise de correspondência múltipla para destacar e evidenciar os achados da pesquisa.

\subsection{Estatísticas descritivas}

Em virtude dos dados categóricos da amostra, as estatísticas descritivas se concentram prioritariamente na distribuição de frequências e testes de diferença de grupos chi-quadrado (Fávero \& Belfiore, 2017). Ambas as análises são baseadas no comportamento entre as aquisições relacionadas à Covid-19 e as demais dispensas.

Sobre essas perspectivas, apenas 5,92\% do volume total de dispensas de licitação em 2020 destinouse ao combate à Covid-19, ao passo que os outros 94,08\% remontam às aquisições corriqueiras. Cabe frisar que o desconhecimento acerca dos reflexos da pandemia levou o Poder Legislativo a criar essa forma de contratação, que já representa aproximadamente uma em cada vinte compras por dispensa, movimento explicado como resposta contingencial em períodos de inquietação (Chenhall, 2003; Otley, 2016).

Quanto à categorização institucional, a maior parcela de compras para combater a Covid-19 
concentra-se em conjuntos ministeriais ligados à manutenção econômica e à segurança. Esse resultado indica como a perspectiva contingencial é capaz de promover um efeito reativo nas instituições, adequando suas práticas gerenciais às necessidades impostas pelo ambiente (Espejo, 2008).

Nesse contexto contingencial, o papel das instituições de ensino se sobressai, especialmente quando se considera a participação das aquisições para enfrentar a pandemia $(38,19 \%)$ em relação às demais dispensas (17,14\%). Observa-se, portanto, que uma necessidade do ambiente impôs uma reformulação do papel dessas instituições.

Além disso, os dados comparativos entre o amparo legal e a categorização institucional também apresentam diferença significativa $\left(\square^{2}(5)=30,487\right.$, p-valor $\left.<0,000\right)$, o que pode ser visualizado por meio da Tabela 3, na qual se nota que a quantidade de ministérios relacionados com questões econômicas/desenvolvimentistas e de segurança se destaca em ambas as aquisições públicas.

Tabela 3:

Distribuição Institucional

\begin{tabular}{l|c|c|c|c|c|c}
\multicolumn{1}{c|}{ Descrição } & \multicolumn{2}{c|}{ Covid-19 } & \multicolumn{2}{c}{ Demais Dispensas } & \multicolumn{2}{c}{ Total Geral } \\
\hline Legislativo & 4 & $0,02 \%$ & 1.119 & $0,28 \%$ & 1.123 & $0,27 \%$ \\
\hline Contro/Administr & 384 & $1,55 \%$ & 18.235 & $4,62 \%$ & 18.619 & $4,44 \%$ \\
\hline Saúde & 2.317 & $9,33 \%$ & 19.037 & $4,82 \%$ & 21.354 & $5,09 \%$ \\
\hline Judiciário & 554 & $2,23 \%$ & 22.217 & $5,63 \%$ & 22.771 & $5,43 \%$ \\
\hline Educação & 12.082 & $48,68 \%$ & 67.642 & $17,14 \%$ & 79.724 & $19,01 \%$ \\
\hline Outros Ministérios & 9.480 & $38,19 \%$ & 266.355 & $67,50 \%$ & 275.835 & $65,76 \%$ \\
\hline Total Geral & 24.821 & $100,00 \%$ & 394.605 & $100,00 \%$ & 419.426 & $100,00 \%$ \\
\hline
\end{tabular}

Fonte: Elaborado pelos Autores

Sobre as fontes de recursos que custeiam as dispensas, foram notadas diferenças entre os grupos $\left(\square^{2}(5)=9,8979\right.$, p-valor $\left.=0,0782\right)$, no limite de significância. Dito isso, em relação à origem dos recursos que financiam as aquisições públicas no contexto desta pesquisa, percebe-se o uso modesto de fontes de recursos próprios, arrecadados diretamente pelos órgãos que executam a despesa, visto que, de maneira ampla, os repasses do tesouro nacional representam a maior fonte de recursos, independentemente do amparo legal da dispensa.

Isso pode ser justificado pela ausência de crédito orçamentário nas fontes de recursos próprios, específicos para enfrentar a pandemia, sobretudo na ação governamental $21 \mathrm{C} 0$, criada especificamente para essa finalidade (Controladoria Geral da União, 2021). Isto é, os recursos orçamentários para combater a pandemia não foram alocados em fontes próprias.

Além disso, à luz do princípio orçamentário da anualidade (Giacomoni, 2019), os recursos próprios somente podem ser empenhados após a arrecadação do valor financeiro correspondente, o que explica o leve aumento nas compras públicas para enfrentar o coronavírus no decorrer do exercício. Logo, percebe-se que a ausência de previsão na ação orçamentária e a baixa arrecadação nos primeiros meses de 2020 limitaram o uso de recursos próprios para enfrentar a Covid-19.

Esses fatores adiam o uso desse tipo de recurso, o que pode ser verificado com o auxílio da Figura 1 , na qual se observa o afrouxamento dos procedimentos licitatórios após março, com a promulgação da Lei 13.979/2020 (Lei 13.979, 2020).

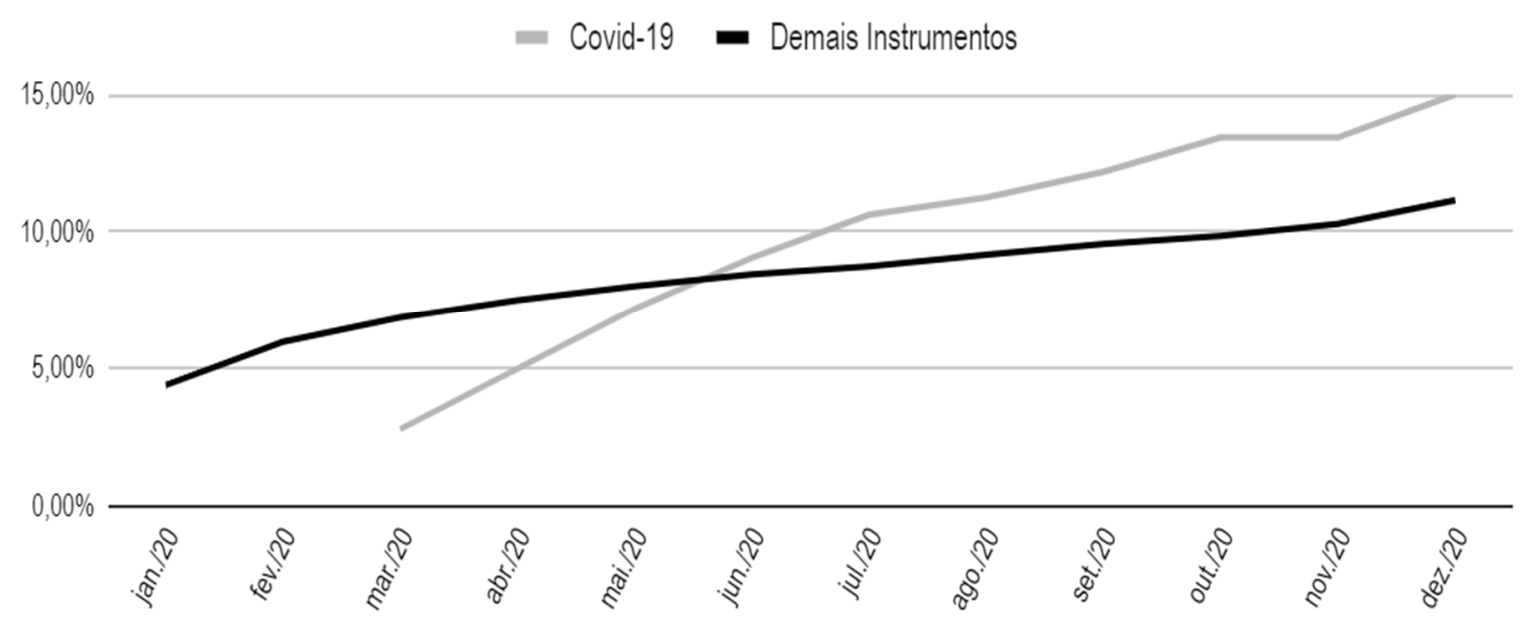

Figura 1: Crescimento no Uso de Recursos Próprios para Enfrentamento à Pandemia

Fonte: Elaborado pelos autores 
Saliente-se que a classificação por fonte é essencial para evidenciar a origem dos recursos que custearam a despesa. Isso permite um levantamento apurado sobre o modo como as atividades organizacionais são geridas (Giacomoni, 2019; Kaliuha, 2016), denotando a dependência de recursos do tesouro para financiar as atividades de enfrentamento à pandemia $(55,12 \%)$, visto que o uso de recursos próprios é inferior a $5 \%$, enquanto as demais despesas são responsáveis por quase um quinto das dispensas, conforme demonstrado na Tabela 4.

Tabela 4:

Distribuição por Fonte de Recursos

\begin{tabular}{l|c|c|c|c|c|c}
\hline \multicolumn{1}{c|}{ Descrição } & \multicolumn{2}{c|}{ Covid-19 } & \multicolumn{2}{c}{ Demais Dispensas } & \multicolumn{2}{c}{ Total Geral } \\
\hline Taxas & 3 & $0,01 \%$ & 573 & $0,15 \%$ & 576 \\
\hline Contribuições & 120 & $0,48 \%$ & 7.048 & $1,79 \%$ & 7.168 \\
\hline Operações de Crédito & 3.795 & $15,29 \%$ & 55.131 & $13,97 \%$ & 58.926 & $14,71 \%$ \\
\hline Recursos Próprios & 1.177 & $4,74 \%$ & 72.441 & $18,36 \%$ & 73.618 & $17,55 \%$ \\
\hline Outras Receitas & 6.044 & $24,35 \%$ & 81.060 & $20,54 \%$ & 87.104 & $20,77 \%$ \\
\hline Tesouro & 13.682 & $55,12 \%$ & 178.352 & $45,20 \%$ & 192.034 & $45,78 \%$ \\
\hline Total Geral & 24.821 & $100,00 \%$ & 394.605 & $100,00 \%$ & 419.426 & $100,00 \%$ \\
\hline
\end{tabular}

Fonte: Elaborado pelos Autores

Por sua vez, os programas de governo e o amparo licitatório também se distribuem de forma claramente distinta $\left(\square^{2}(4)=53,193, p\right.$-valor $\left.<0,000\right)$. Do mesmo modo, na comparação entre as aquisições para enfrentar a Covid-19 e as demais dispensas, conforme a Tabela 5, os programas ligados à educação são responsáveis por $39 \%$ das compras para combater a pandemia, enquanto a educação representa apenas $13,97 \%$ das demais dispensas.

Tabela 5:

Distribuição por Programas de Governo

\begin{tabular}{l|c|c|c|c|c|c}
\hline \multicolumn{1}{c|}{ Descrição } & \multicolumn{2}{c|}{ Covid-19 } & \multicolumn{2}{c}{ Demais Dispensas } & \multicolumn{2}{c}{ Total Geral } \\
\hline Saúde & 4.303 & $17,34 \%$ & 21.753 & $5,51 \%$ & 26.056 & $6,21 \%$ \\
\hline Economia/Desenvolv. & 239 & $0,96 \%$ & 25.879 & $6,56 \%$ & 26.118 & $6,23 \%$ \\
\hline Segurança & 508 & $2,05 \%$ & 42.783 & $10,84 \%$ & 43.291 & $10,32 \%$ \\
\hline Educação & 9.681 & $39,00 \%$ & 55.145 & $13,97 \%$ & 64.826 & $15,46 \%$ \\
\hline Outros Programas & 10.090 & $40,65 \%$ & 249.045 & $63,11 \%$ & 259.135 & $61,78 \%$ \\
\hline Total Geral & 24.821 & $100,00 \%$ & 394.605 & $100,00 \%$ & 419.426 & $100,00 \%$ \\
\hline
\end{tabular}

Fonte: Elaborado pelos Autores

Diante do alto volume de aquisições realizadas por programas ligados à educação, demonstrado pelos 39\% indicados na Tabela 5, os resultados foram segmentados de acordo com o objeto de gasto, indicando que as compras nesses programas governamentais se concentraram no enfrentamento à pandemia. Assim, nota-se uma mudança no padrão de compra. De acordo com a Figura 2, enquanto as demais dispensas estão voltadas para as contratações de serviços terceirizados, as dispensas que utilizaram a Lei 13.979/2020 (Lei 13.979, 2020) como amparo legal concentram-se em itens como materiais hospitalares, laboratoriais, farmacológicos e de higiene, dentre outros.

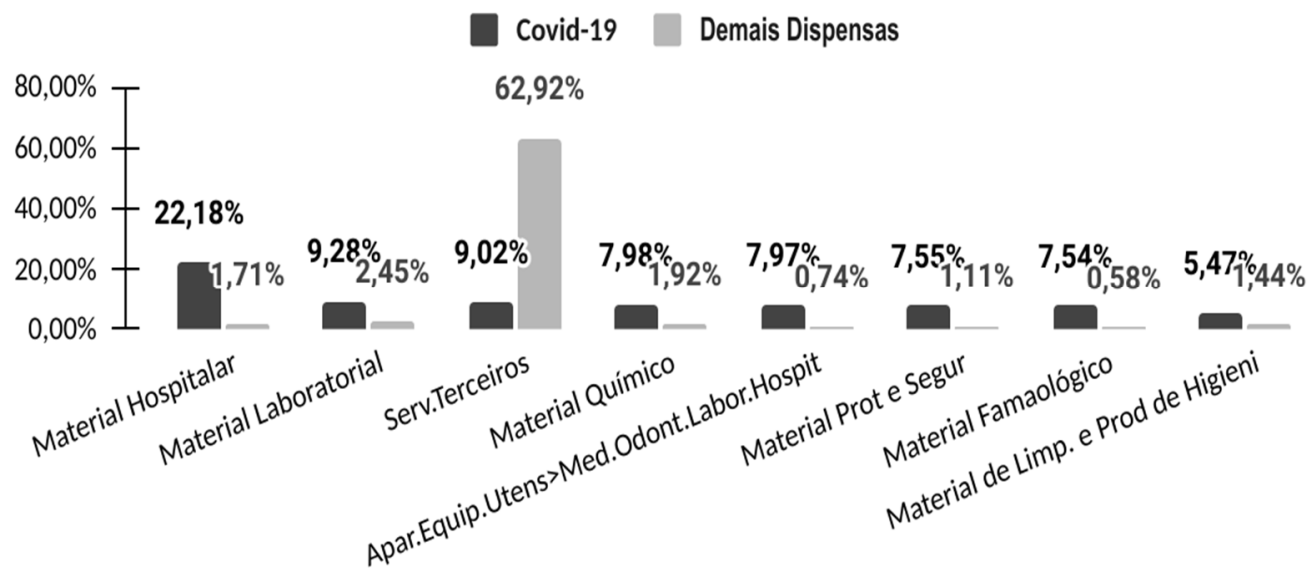

Figura 2: Objetos das Aquisições nos Programas Ligados à Educação

Nota: Os dados demonstram 76,98\% das compras para enfrentamento à Covid-19 e 72,88\% das demais dispensas de licitação.

Fonte: Elaborado pelos autores 
Novamente o aspecto contingencial é ressaltado. Em vista do viés ambiental gerado pela pandemia, os órgãos públicos precisaram adequar sua rotina e aferir as aquisições prioritárias para seus planos de trabalho (Wadongo \& Abdel-Kader, 2014). Nesse contexto, as universidades públicas se mostraram proeminentes na criação de insumos para lidar com a disseminação do vírus, bem como na produção científica para identificar e desenvolver mecanismos de combate à Covid-19.

Por sua vez, a classificação funcional-programática, responsável por indicar as ações institucionais, demonstra que, para combater o coronavírus, as áreas de gastos foram reordenadas, demonstrando o aparato contingencial necessário para mitigar a disseminação do vírus, independentemente do setor funcional-programático de exercício da instituição. Ademais, cabe frisar que os programas relacionados à saúde representam cerca de 17,34\% das dispensas referentes à Covid-19.

Cabe esclarecer que, ao considerar os demais instrumentos licitatórios, os gastos em órgãos ligados à saúde representam $42,51 \%$ dos valores empenhados para combater a pandemia. Isso indica que os valores empenhados pelo Ministério da Saúde são mais expressivos, mas em menor quantidade de compras.

Acerca das funções de governo, também foram verificadas diferenças nos padrões de aquisição $\left(\square^{2}(8)=57,82\right.$, p-valor $\left.<0,000\right)$. Os resultados indicam uma leve diferença em comparação com os programas orçamentários apresentados anteriormente. Ocorre que as funções orçamentárias ligadas à saúde têm grande representação nas compras públicas para combater o coronavírus $(31,07 \%)$, enquanto os programas orçamentários que possuem o mesmo objetivo se resumem a aproximadamente 17\%, como mencionado anteriormente.

Isso se deve às aplicações distintas entre funções e programas orçamentários. Nesse sentido, a função está intimamente ligada à competência institucional do órgão, enquanto os programas orçamentários se voltam à articulação de ações para alcançar objetivos e metas previstos nas leis orçamentárias (Ministério da Fazenda, 2019). Logo, ainda que estejam ligados ao mesmo conceito, as funções e programas têm aplicações distintas que se tornam evidentes em um contexto que demanda ações contingentes dos gestores públicos, conforme distribuição por função orçamentária na Tabela 6.

Tabela 6:

Distribuição por Função Orçamentária

\begin{tabular}{l|c|c|c|c|c|c}
\multicolumn{1}{c|}{ Descrição } & \multicolumn{2}{c|}{ Covid-19 } & \multicolumn{2}{c}{ Demais Dispensas } & \multicolumn{2}{c}{ Total Geral } \\
\hline Habitação & 8 & $0,03 \%$ & 2.204 & $0,56 \%$ & 2.212 & $0,53 \%$ \\
\hline Cultura & 12 & $0,05 \%$ & 2.931 & $0,74 \%$ & 2.943 & $0,70 \%$ \\
\hline Previdência & 247 & $1,00 \%$ & 11.634 & $2,95 \%$ & 11.881 & $2,83 \%$ \\
\hline Economia/Desenvolv. & 318 & $1,28 \%$ & 13.589 & $3,44 \%$ & 13.907 & $3,32 \%$ \\
\hline Agricultura & 85 & $0,34 \%$ & 20.595 & $5,22 \%$ & 20.680 & $4,93 \%$ \\
\hline Saúde & 7.713 & $31,07 \%$ & 32.576 & $8,26 \%$ & 40.289 & $9,61 \%$ \\
\hline Educação & 6.686 & $26,94 \%$ & 54.385 & $13,78 \%$ & 61.071 & $14,56 \%$ \\
\hline Outras Funções & 2.500 & $10,07 \%$ & 119.567 & $30,30 \%$ & 122.067 & $29,10 \%$ \\
\hline Segurança Pública & 7.252 & $29,22 \%$ & 137.124 & $34,75 \%$ & 144.376 & $34,42 \%$ \\
\hline Total Geral & 24.821 & $100,00 \%$ & 394.605 & $100,00 \%$ & 419.426 & $100,00 \%$ \\
\hline
\end{tabular}

Fonte: Elaborado pelos Autores

Quanto à classificação de acordo com a natureza da despesa, inicialmente as categorias econômicas não se afastam nitidamente, mas estatisticamente os grupos apresentam a significância esperada $\left(\square^{2}(1)=6,1723\right.$, p-valor $\left.=0,0130\right)$. Ademais, na Tabela 7 em ambos os amparos legais as despesas com custeio predominam.

Tabela 7:

Distribuição por Categoria Econômica

\begin{tabular}{l|c|c|c|c|c|c}
\multicolumn{1}{c|}{ Descrição } & \multicolumn{2}{c|}{ Covid-19 } & \multicolumn{2}{c}{ Demais Dispensas } & \multicolumn{2}{c}{ Total Geral } \\
\hline Capital & 3.288 & $13,25 \%$ & 31.954 & $8,10 \%$ & 35.242 & $8,40 \%$ \\
\hline Corrente & 21.533 & $86,75 \%$ & 362.651 & $91,90 \%$ & 384.184 & $91,60 \%$ \\
\hline Total Geral & 24.821 & $100,00 \%$ & 394.605 & $100,00 \%$ & 419.426 & $100,00 \%$ \\
\hline
\end{tabular}

Fonte: Elaborado pelos Autores

Ainda de acordo com a classificação pela natureza da despesa, nota-se uma diferença entre os grupos de amparo legal e o elemento de despesa $\left(\square^{2}(6)=165,22\right.$, p-valor $\left.<0,000\right)$. Os dados indicam que os materiais de consumo são responsáveis pela notória maioria das aquisições para combater a Covid-19, especialmente pela necessidade de adquirir materiais de higiene e limpeza, bem como itens de proteção individual. 
Essa classificação por natureza da despesa demonstra como o governo intervém, seja pela formação de patrimônio, seja pelos gastos correntes, assim como indica o tipo de objeto de aquisição (Giacomoni, 2019). Nessa perspectiva, percebe-se uma mudança nos padrões de consumo, em que os itens assumem a maioria absoluta das compras para combater a Covid-19, ao passo que os serviços de terceiros eram superiores a $50 \%$ das aquisições de dispensa, mas representavam apenas $11,75 \%$ das compras relacionadas ao coronavírus.

Tabela 8:

Distribuição por Elemento de Despesa

\begin{tabular}{l|c|c|c|c|c|c}
\multicolumn{1}{c|}{ Descrição } & \multicolumn{2}{c|}{ Covid-19 } & \multicolumn{2}{c}{ Demais Dispensas } & \multicolumn{2}{c}{ Total Geral } \\
\hline Pessoal & & & 105 & $0,03 \%$ & 105 & $0,03 \%$ \\
\hline Bolsas/Diárias & & & 269 & $0,07 \%$ & 269 & $0,06 \%$ \\
\hline Obras e Imob & 23 & $0,09 \%$ & 1.153 & $0,29 \%$ & 1.176 & $0,28 \%$ \\
\hline Mat. Perman & 3.230 & $13,01 \%$ & 25.905 & $6,56 \%$ & 29.135 & $6,95 \%$ \\
\hline Outros Elem & 408 & $1,64 \%$ & 36.931 & $9,36 \%$ & 37.339 & $8,90 \%$ \\
\hline Mat. Consum & 18.243 & $73,50 \%$ & 129.818 & $32,90 \%$ & 148.061 & $35,30 \%$ \\
\hline Serviços Terc & 2.917 & $11,75 \%$ & 200.424 & $50,79 \%$ & 203.341 & $48,48 \%$ \\
\hline Total Geral & 24.821 & $100,00 \%$ & 394.605 & $100,00 \%$ & 419.426 & $100,00 \%$ \\
\hline
\end{tabular}

Fonte: Elaborado pelos Autores

Por fim, a classificação de acordo com a categoria valor, também distinta entre grupos $\left(\square^{2}(1)=24,733\right.$, p-valor $<0,000$ ), expõe como a rigidez de limites mantém os gastos públicos dentro da razoabilidade necessária a cada modalidade licitatória (Vieira et al., 2018). Isto é, a partir da liberação das aquisições para confrontar o vírus, conforme dispôs a Medida Provisória 961/2020 (Medida Provisória 961, 2020), os valores irrisórios abaixo de $\mathrm{R} \$ 17.600$ foram claramente superados, enquanto às demais aquisições que preservam os limites anteriores contiveram suas despesas, conforme distribuição por categoria de valor na Tabela 9 .

Tabela 9:

Distribuição por Categoria de Valor

\begin{tabular}{l|c|c|c|c|c|c}
\multicolumn{1}{c|}{ Descrição } & \multicolumn{2}{c|}{ Covid-19 } & \multicolumn{2}{c}{ Demais Dispensas } & \multicolumn{2}{c}{ Total Geral } \\
\hline Vultoso & 16.097 & $64,85 \%$ & 91.237 & $23,12 \%$ & 107.334 & $25,59 \%$ \\
\hline Não Vultoso & 8.724 & $35,15 \%$ & 303.368 & $76,88 \%$ & 312.092 & $74,41 \%$ \\
\hline Total Geral & 24.821 & $100,00 \%$ & 394.605 & $100,00 \%$ & 419.426 & $100,00 \%$ \\
\hline
\end{tabular}

Fonte: Elaborado pelos Autores

Os resultados demonstram que, especialmente na classificação funcional-programática, houve diferenças robustas na categorização das despesas, ao mesmo tempo que a classificação quanto à natureza da despesa manteve os comportamentos de compra assemelhados. Tais diferenças levam à assunção de que as atividades finalísticas e os objetivos institucionais são divergentes entre os órgãos que realizam as aquisições para enfrentar a pandemia. Todavia, os objetos de gastos refletidos na natureza das despesas foram aproximados.

Ou seja, além da classificação mediante a natureza da despesa, as outras classificações não apresentam padrões destoantes de aquisição entre compras para enfrentar a Covid-19 e demais despesas corriqueiras. Isso indica que, ainda que existam objetivos institucionais divergentes, o momento exige uma centralidade de objetivos, visando conjugar esforços para confrontar a pandemia.

As mudanças nos padrões de classificação das compras explicam a alteração no comportamento das instituições analisadas (Cavichioli et al., 2018). Isto é, a influência imprevisível de uma crise sistêmica decorrente de uma pandemia acabou se revelando mais um aspecto do ambiente externo que atinge diretamente as contingências organizacionais e se reflete em novos hábitos de compra (Wadongo \& AbdelKader, 2014).

\subsection{Análise de correspondência múltipla}

Para identificar possíveis associações com as características das compras realizadas para enfrentar a pandemia da Covid-19, utilizou-se a análise de correspondência múltipla como ferramenta de análise de dados categóricos, o que permitiu elaborar um mapa perceptual entre as variáveis e suas respectivas categorias (Fávero \& Belfiore, 2017).

Trata-se de um método de representação de linhas e colunas como coordenadas de um gráfico. Por meio dessa técnica é possível identificar similaridades e diferenças no comportamento de variáveis, representados em diagramas de dispersão que permitem que as características das variáveis e categorias 
sejam dispostas como pontos em relação a eixos de coordenadas ortogonais (Fávero \& Belfiore, 2017). Diante disso, nota-se que a vantagem dessa técnica é a possibilidade de verificar a associação entre variáveis observáveis e objetos, criando mapas que permitem perceber o comportamento de diferentes características de um mesmo fenômeno (Hair et al., 2009).

Posto isso, e considerando que todas as associações entre variáveis foram significativas, conforme os testes chi-quadrado $\left(\square^{2}\right)$ realizados durante as análises descritivas, a análise de correspondência múltipla tomou como base a verificação da variância acumulada, conforme a Tabela 10, decorrente dos autovalores que correspondem à categorização ortogonal das variáveis.

Tabela 10:

Autovalores

\begin{tabular}{l|c|c|c}
\hline \multicolumn{1}{|c|}{ Dimensão } & Autovalor & Variância & Variância Acumulada \\
\hline Dim.1 & 0,3456 & 8,9181 & 8,9181 \\
\hline $\operatorname{Dim} .2$ & 0,3167 & 8,1716 & 17,0899 \\
\hline Dim.3 & 0,2472 & 6,3802 & 23,4700 \\
\hline
\end{tabular}

\begin{tabular}{l|l|c|c}
\hline Dim.31 & 0,0084 & 0,2168 & 100,0000 \\
\hline
\end{tabular}

Fonte: Elaborado pelos Autores

Tendo em vista as duas dimensões iniciais, o mapa perceptual apresenta uma variância acumulada de aproximadamente $17 \%$, aquém do desejado, mas considerado suficiente para a obtenção aproximada das características das aquisições decorrentes do confronto com o coronavírus. Cabe salientar que o levantamento completo de todas as perspectivas possíveis levaria em conta 31 dimensões.

Logo, por meio da distribuição gráfica das variáveis, representada na Figura 3, nota-se que foram formados dois grupos nitidamente distintos. O primeiro, envolto em um círculo, agrupa as classificações funcionais e programáticas utilizadas nos empenhos, além de uma característica institucional correspondente ao órgão máximo de origem da despesa.

Por outro lado, estão associadas todas as demais variáveis, com atenção especial ao próprio amparo legal da despesa, seja a Covid-19, seja as demais dispensas. Isso corrobora as indicações feitas nas análises descritivas quanto à correspondência do amparo legal e os aspectos da natureza da despesa e fonte de recursos dos empenhos.

Novamente cabe salientar que essa associação indica que o uso dos recursos públicos em meio à pandemia está relacionado a aquisições particulares, discriminadas especialmente pelos elementos da despesa, que podem envolver compras de materiais de higiene e limpeza, produtos hospitalares, materiais laboratoriais, equipamentos de proteção individual ou, ainda, os próprios respiradores.

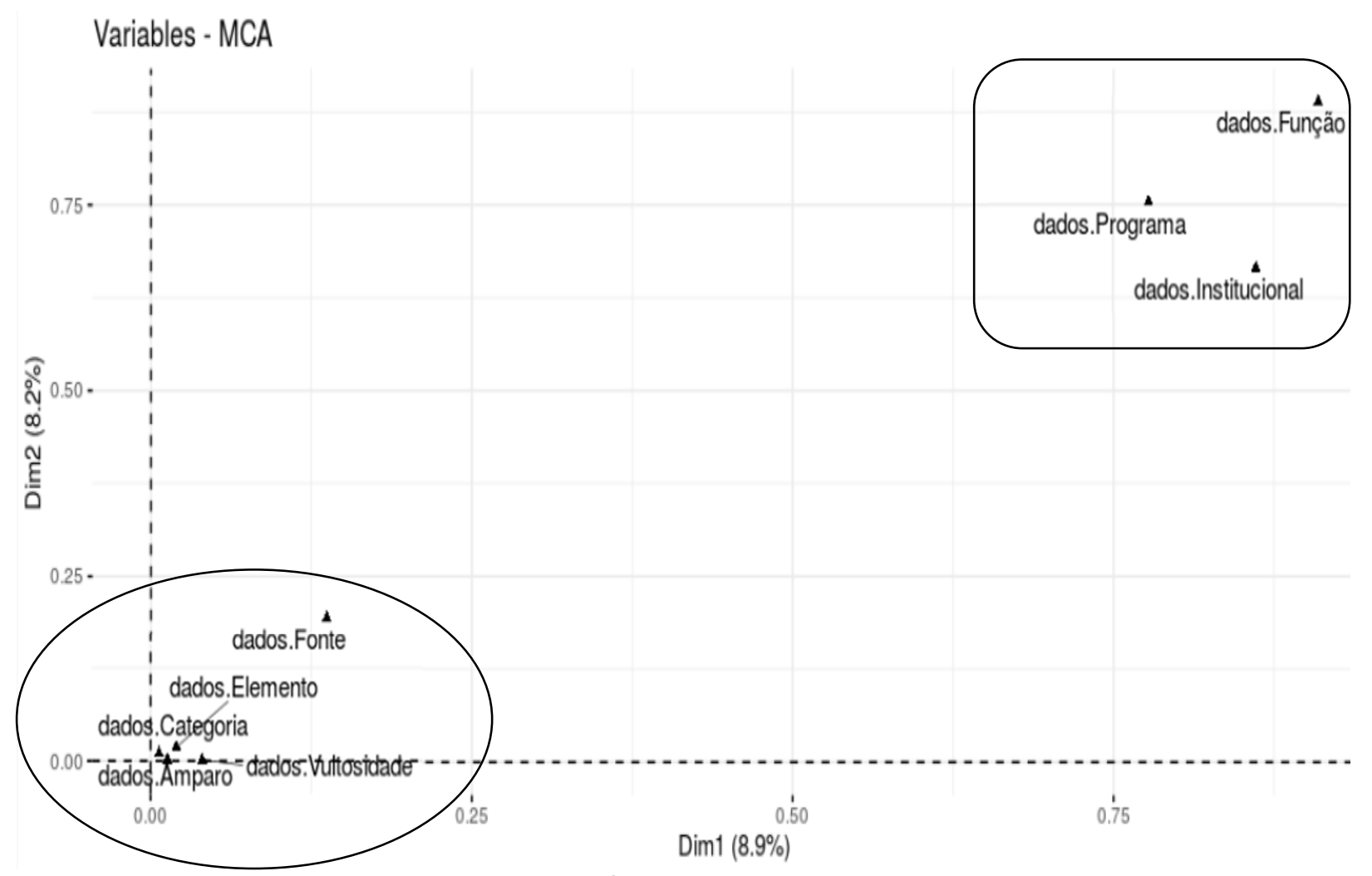

Figura 3: Mapa Perceptual de Representação das Variáveis

Fonte: Elaborado pelos Autores 
Ao ampliar a análise, a distribuição por categorias, consoante à Figura 4, permite compreender que tanto o amparo pelas compras relacionadas à Covid-19 quanto as demais dispensas apresentam associações distintas. O mapa indicado foi propositalmente traçado de maneira que se observa a distância perceptual entre esses aspectos.

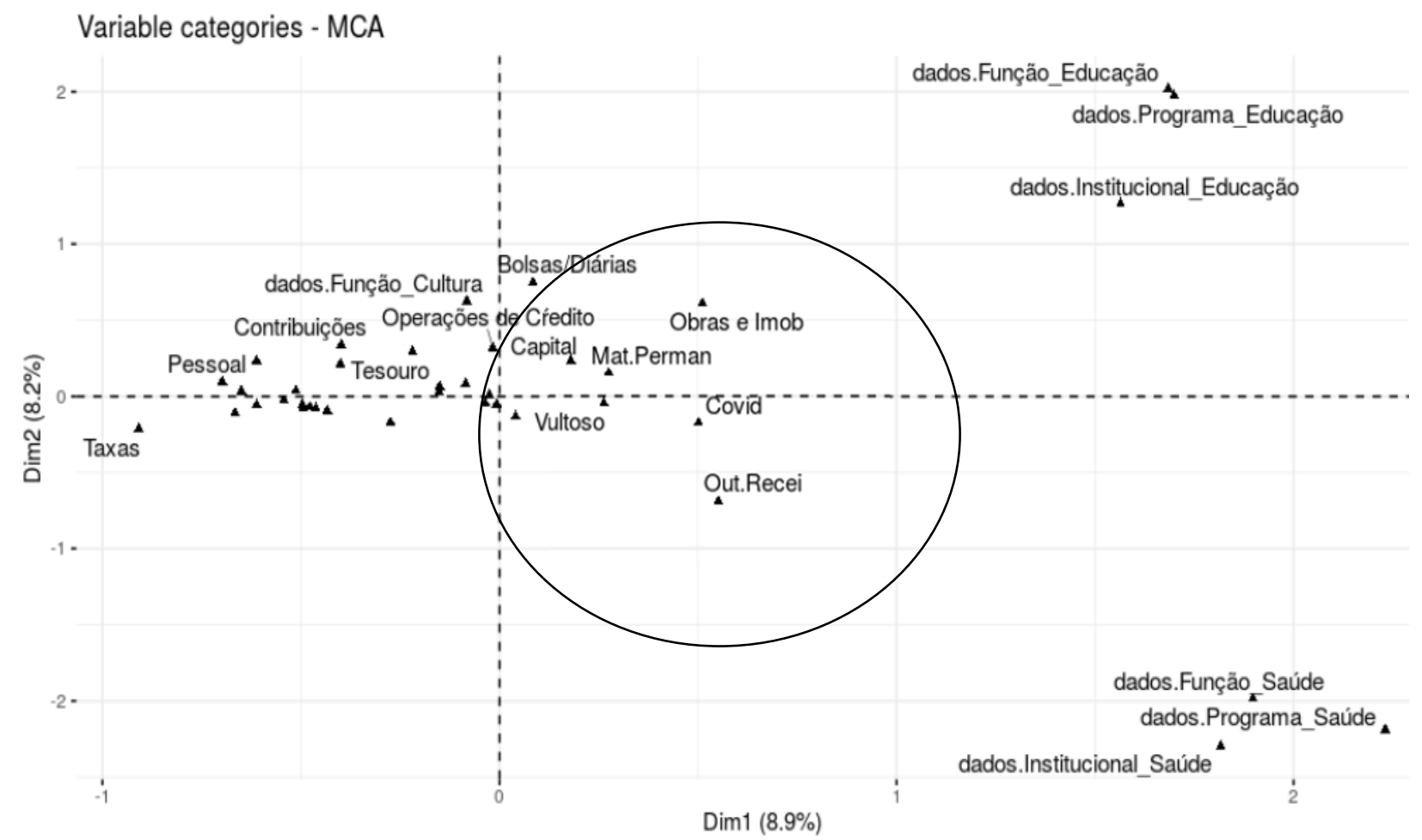

Figura 4: Mapa Perceptual de Distribuição das Categorias Fonte: Elaborado pelos Autores

Cabe esclarecer que, embora a variável "amparo" indique uma associação com os elementos e categorias econômicas dos empenhos, isso não pode ser diretamente relacionado às compras referente à Covid-19. Esse resultado pode ser explicado pelo lapso temporal analisado, em que a movimentação funcional-programática e institucional ainda se adaptava para acolher novos modelos de compra. Contudo, apesar do baixo volume de aquisições, suas características já denotam um comportamento contingencial (Cavichioli et al., 2018) inerente às necessidades de atuação tempestiva para frear a disseminação da doença.

Por outro lado, ao considerar que a Lei 13.979/2020 (Lei 13.979, 2020) permite a aquisição mediante um procedimento licitatório simplificado e retira os limites impostos pela lei de licitações, as compras se mostraram mais vultosas em relação às demais aquisições. Por isso, a Figura 4 demonstra que, ligeiramente ao centro da figura, as compras vultosas são as que mais se aproximam dos empenhos para combater o coronavírus.

Por fim, na Figura 5, o volume de aquisições relacionadas à Covid-19 ainda se mostra consideravelmente inferior às demais compras, quando associado ao total de observações utilizadas no estudo, representado pela mancha em cinza do gráfico. Nesse sentido, com o auxílio do círculo tracejado, fica evidente que a quantidade de despesas para enfrentar a pandemia ainda é notadamente menor em relação às demais compras.

Realizados os levantamentos cabíveis, cumpre acentuar que se descobriu como maior mérito desta pesquisa a indicação de que as características funcionais-programáticas se comportam de modo distinto em relação às características de natureza da despesa. Isso evidencia as diferenças de propósitos nas ações institucionais dos órgãos de governo, mas também similaridades quanto aos objetos de gasto no decorrer de 2020, período de expansão da doença no Brasil. Destarte, em decorrência do ambiente externo, incerto e inédito, abre-se mão dos padrões de compra e dos objetivos institucionais verificados nas demais compras, atendendo novas necessidades públicas e colocando novos itens na pauta de aquisição das instituições (Wadongo \& Abdel-Kader, 2014).

Assume-se, portanto, que as características das compras para combater a pandemia têm condições ímpares, distintas das aquisições tradicionais. Isso se explica, dentre outras razões, pela flexibilização das condições licitatórias, cujos valores de aquisição se expandiram, justificando a distinção categórica nos tipos de dispensa de licitação. 


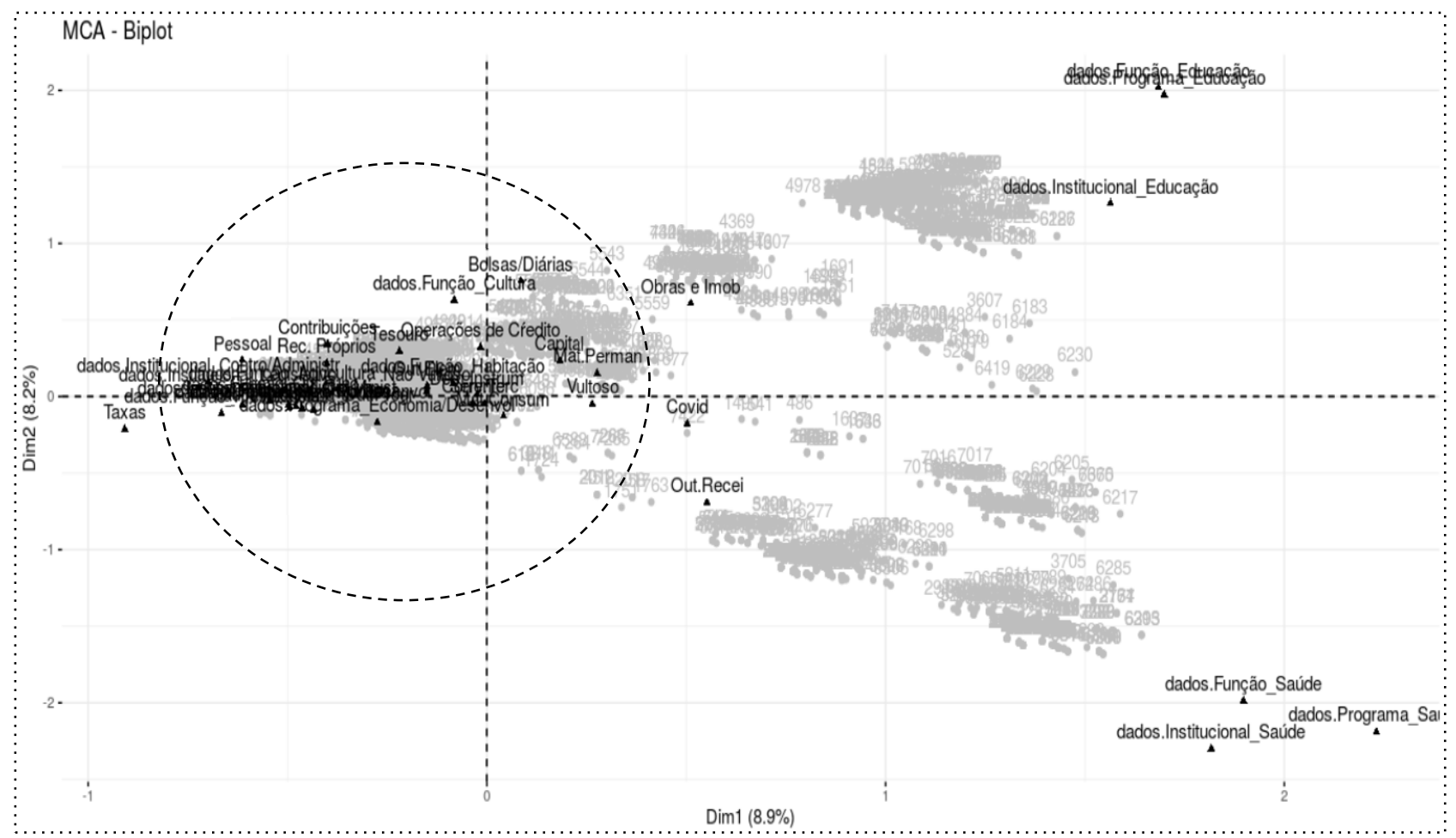

Figura 5: Mapa Perceptual de Distribuição das Observações Frente às Categorias

Fonte: Elaborado pelos Autores

Por outro lado, ao utilizar os mapas perceptuais verifica-se que as variáveis funcionais e programáticas não se associam ao amparo legal utilizado. Ou seja, independentemente dos propósitos de atuação governamental, as referências de dispensas de licitação não apresentam distinções evidentes.

Tendo em conta esses dados, este estudo se mostra inédito ao relacionar de modo pragmático a distinção na ação governamental de confronto à pandemia, cujos resultados demonstram uma associação nítida entre os objetivos orçamentários, representados pela categoria econômica e pelos elementos de despesa, no amparo legal utilizado, seja para combater o coronavírus pela Lei 13.979/2020 (Lei 13.979, 2020), seja em relação às demais dispensas de licitação, abrigadas na Lei 8.666/1993 (Lei 8.666, 1993).

\section{Conclusões}

O período pandêmico decorrente da Covid-19 alterou a vida em sociedade das mais diferentes formas e intensidades, inclusive quanto às prioridades governamentais. Nesse sentido, o governo, diante de uma crise de saúde, precisou redirecionar sua atuação, utilizando a máquina pública para combater o coronavírus.

O comportamento da administração pública para enfrentar um obstáculo advindo do ambiente externo pode ser explicado por meio da teoria contingencial, em particular quanto ao reordenamento de prioridades e objetivos do governo, além da revisão sobre o modo como as instituições seriam utilizadas. Logo, mesmo órgãos com pautas alheias às questões de saúde se viram diante da necessidade de atuar em prol de um objetivo comum.

Diante desse cenário, esta pesquisa analisou as características das aquisições públicas por meio de dispensa de licitação para enfrentar a pandemia de Covid-19, mediante uma análise de variáveis categóricas de órgãos públicos federais de todo o Brasil durante 2020. Para isso, foram feitas análises descritivas sobre as frequências de distribuição das compras para enfrentar a Covid-19, além de mapas perceptuais obtidos por análises de correspondência múltipla.

Os achados desta pesquisa foram condizentes com o indicado pelo referencial teórico. Nota-se uma diferença entre os objetivos institucionais (as ações concernentes a cada órgão), mas há certa sintonia na aplicação dos recursos. Isto é, independentemente dos propósitos de cada instituição, percebem-se similaridades no uso dos recursos quando o tema é Covid-19, indicando um padrão de compra uníssono.

Do ponto de vista prático, constatou-se que a quantidade de aquisições voltadas para enfrentar a pandemia ainda é modesta em relação às demais dispensas de licitação. Entretanto, o custo dessas aquisições é elevado, sobretudo por causa do afrouxamento de limites promovido pela Lei 13.979/2020 (Lei 13.979, 2020).

Além disso, a proximidade entre programas governamentais demonstra que eventuais ajustes orçamentários poderiam ser aplicados, mesmo que mediante créditos adicionais, o que ajustaria o componente programático ao funcional. Cabe salientar que, de acordo com os resultados, os programas orçamentários se aproximam, ao passo que a classificação funcional mantém a distinção esperada entre as 
instituições.

Portanto, este estudo se mostra inédito ao apontar uma mudança nas características das compras para combater a pandemia, especialmente diante das incertezas do ambiente externo, que são fundamentais para explicar os aspectos contingenciais que modificaram as pautas das instituições públicas e alinharam seus objetivos.

Acredita-se que os achados deste trabalho sejam importantes em diferentes perspectivas, quer pelo uso da teoria contingencial em entidades do setor público que lidam com as adversidades vivenciadas em 2020, quer pela compreensão alcançada sobre as classificações existentes que direcionam as atividades públicas e, consequentemente, o dispêndio de recursos.

Contudo, este estudo não é imune a limitações, especialmente quanto ao escopo, que se limita ao âmbito federal, considerando que convênios e transferências voluntárias podem oferecer maior compreensão sobre as características dessas despesas também em estados e municípios. Assim sendo, sugere-se que para futuras pesquisas a amostra seja ampliada e novas características sejam incluídas, como a capacidade operacional das instituições ou fatores políticos.

\section{Referências}

Andrews, R., Beynon, M. J., \& McDermott, A. M. (2016). Organizational capability in the public sector: a configurational approach. Journal of Public Administration Research and Theory, 26(2), 239-258.

https://doi.org/10.5465/ambpp.2013.16224abstract

Beuren, I. M., \& Fiorentin, M. (2014). Influência de fatores contingenciais nos atributos do sistema de contabilidade gerencial: um estudo em empresas têxteis do estado Rio Grande do Sul. Revista de Ciências da Administração, 16(38), 196-212. https://doi.org/10.5007/2175-8077.2014v16n38p195

Burns, T., \& Stalker, G. M. (1961). The management of innovation. London, UK: Tavistock.

Cavichioli, D., Dall'asta, D., Fiirst, C., \& Baldissera, J. F. (2018). Contingency factors that affect the implementation of the Public Sector Cost Information Subsystem (SICSP) in the perception of municipal controllers and accountants. Advances in Scientific and Applied Accounting, 11(2), 188-204. http://dx.doi.org/10.14392/asaa.2018110201

Chenhall, R. H. (2003). Management control systems design within its organizational context: findings from contingency-based research and directions for the future. Accounting, organizations and society, 28(2-3), 127-168. https://doi.org/10.1016/S0361-3682(01)00027-7

Christensen, M., \& Yoshimi, H. (2003). Public sector performance reporting: new public management and contingency theory insights. Government Auditing Review, 10(3), 71-83.

Controladoria Geral da União. (2021). Portal da Transparência. Recuperado de http://www.portaltransparencia.gov.br/despesas/programa-eacao $?$ acao $=21 \mathrm{C} 0 \&$ ordenarPor $=$ programa\&direcao $=$ asc

Costa Netto, Y. W. E. D. (2017). A relação entre poder intraorganizacional e a efetividade de mecanismos de governança de TI: um estudo de caso em uma organização pública do Rio Grande do Sul. (Dissertação de Mestrado), Pontifícia Universidade Católica do Rio Grande do Sul, Porto Alegre, RS.

Cretu, D. (2013). The characteristics of the budget process at the level of the local public administration in the rural sector. Management, Economic Engineering in Agriculture \& Rural Development, 13(2), 89-94.

Donaldson, L. (2001). The contingency theory of organizations. Thousand Oaks, CA: Sage.

Espejo, M. M. D. S. B. (2008). Perfil dos atributos do sistema orçamentário contingencial: uma abordagem multivariada. (Tese de Doutorado), Faculdade de Economia, Administração, Contabilidade e Atuária, Universidade de São Paulo, São Paulo, SP.

Fávero, L. P., \& Belfiore, P. (2017). Manual de análise de dados: estatística e modelagem multivariada com Exce $^{\circledR}$, SPSS $^{\circledast}$ e Stata ${ }^{\circledR}$. São Paulo, SP: Elsevier.

Giacomoni, J. (2019). Orçamento governamental: teoria, sistema, processo. São Paulo, SP: Atlas.

Hair, J. F., Black, W. C., Babin, B. J., Anderson, R. E., \& Tatham, R. L. (2009). Análise multivariada de dados (6a ed.). Porto Alegre, RS: Bookman. 
Hickson, D. J., Hinings, C. R., Lee, C. A., Schneck, R. E., \& Pennings, J. M. (1971). A strategic contingencies' theory of intraorganizational power. Administrative Science Quarterly, 216-229.

Ibrahim, M. (2011). The rules of federal budget and final accounts in United Arab Emirates. International Journal of Law and Management, 53(3), 199-206. https://doi.org/10.1108/17542431111133427

Kaliuha, Y. (2016). The budget classification as the basis of the usage of the method of accrual in the public sector. Economics, 2(179), 22-28, 2016. http://dx.doi.org/10.17721/1728-2667.2016/179-2/3

Kassambara, A., \& Mundt, F. (2020). Factoextra: extract and visualize the results of multivariate data analyses. Recuperado de http://www.sthda.com/english/rpkgs/factoextra

Klann, R. C., Kreuzberg, F., \& Beck, F. (2014). Fatores de risco evidenciados pelas maiores empresas listadas na BM\&Bovespa. Revista de Gestão Ambiental e Sustentabilidade, 3(3), 78-89. http://dx.doi.org/10.5585/geas.v3i3.95

Lê, S., Josse, J., \& Husson, F. (2008). Facto MineR: an R package for multivariate analysis. Journal of Statistical Software, 25(1), 1-18. http://dx.doi.org/10.18637/jss.v025.i01

Lei 8.666, de 21 de junho de 1993. (1993). Regulamenta o art. 37, inciso XXI, da Constituição Federal, institui normas para licitações e contratos da Administração Pública e dá outras providências. Diário Oficial da União. Recuperado de http://www.planalto.gov.br/ccivil 03/leis//8666cons.htm

Lei 13.979, de 6 de fevereiro de 2020. (2020). Dispõe sobre as medidas para enfrentamento da emergência de saúde pública de importância internacional decorrente do coronavírus responsável pelo surto de 2019. Diário Oficial da União. Recuperado de http://www.planalto.gov.br/ccivil 03/ ato20192022/2020/lei/l13979.htm

Lima, D. V. (2018). Orçamento, contabilidade e gestão no setor público. São Paulo, SP: Atlas.

Medida Provisória 961, de 6 de maio de 2020. (2020). Autoriza pagamentos antecipados nas licitações e nos contratos, adequa os limites de dispensa de licitação e amplia o uso do Regime Diferenciado de Contratações Públicas - RDC durante o estado de calamidade pública reconhecido pelo Decreto Legislativo ํㅜ 6, de 20 de março de 2020. Diário Oficial da União. Recuperado de http://www.planalto.gov.br/ccivil 03/ ato2019-2022/2020/Mpv/mpv961.htm

Mikesell, J. L., \& Mullins, D. R. (2001). Reforming budget systems in countries of the former Soviet Union. Public Administration Review, 61(5), 548-568. https://doi.org/10.1111/0033-3352.00127

Ministério da Fazenda. (2019). Manual de contabilidade aplicada ao setor público (8a ed.). Brasília, DF: Secretaria do Tesouro Nacional. 2019.

STG. Sistema de Tesouro Gerencial. Secretaria do Tesouro Nacional. (2020). Recuperado de https://tesourogerencial.tesouro.gov.br/servlet/mstrWeb?pg=login

Otley, D. (2016). The contingency theory of management accounting and control: 1980-2014. Management Accounting Research, 31, 45-62. http://doi.org/10.1016/j.mar.2016.02.001

R Foundation. (2010). A language and environment for statistical computing. Recuperado de http://www.Rproject.org

Sell, F. F., Beuren, I. M., \& Lavarda, C. E. F. (2020). Influência de fatores contingenciais no desempenho municipal: evidências inferenciais. Revista de Contabilidade e Organizações, 14, 1-13. https://doi.org/10.11606/issn.1982-6486.rco.2020.164058

Trilha, C. C. S., Alves, G. K., Nunes, R. S. (2018). Evaluation of procurement processes without bidding: a study at a federal university. Nevus, 8(2), 73-86.

Vieira, L., Andrade, D. M., \& Ferreira, P. A. (2018). Estudo do Sistema de cotação eletrônica em uma empresa pública do estado de Minas Gerais. Revista Gestão \& Tecnologia, 18(3), 270-291.

Wadongo, B., \& Abdel-Kader, M. (2014). Contingency theory, performance management and organisational 
effectiveness in the third sector. International Journal of Productivity and Performance Management, 63(6), 680-703. https://doi.org/10.1108/IJPPM-09-2013-0161

Wickham, H. (2007). Reshaping data with the reshape package. Journal of Statistical Software, 21(12), 1-20. https://doi.org/10.18637/jss.v021.i12

\section{NOTAS}

\section{AGRADECIMENTOS}

Os autores agradecem ao Projeto Universal do CNPq, Bolsa de Doutorado da CAPES, Universidade Federal do Paraná e Programa de Pós-Graduação em Contabilidade

\section{CONTRIBUIÇÃO DE AUTORIA}

Concepção e elaboração do manuscrito: Lima Filho, S. S.; Martins, G.D.; Severo Peixe, B.C.

Coleta de dados: Lima Filho, S. S.; Martins, G.D.;

Análise de dados: Lima Filho, S. S.; Martins, G.D.; Severo Peixe, B.C.

Discussão dos resultados: Lima Filho, S. S.; Martins, G.D.; Severo Peixe, B.C.

Revisão e aprovação: Severo Peixe, B.C.

\section{CONJUNTO DE DADOS DE PESQUISA}

O conjunto de dados que dá suporte aos resultados deste estudo está disponível publicamente.

\section{FINANCIAMENTO}

Projeto Universal do CNPq; Bolsa de Doutorado CAPES; Programa de Pós-Graduação em Contabilidade / UFPR; PPGCont. Em conformidade com a Portaria $n^{\circ} 206$, de 4 de setembro de 2018, "o presente trabalho foi realizado com apoio da Coordenação de Aperfeiçoamento de Pessoal de Nível Superior - Brasil (CAPES) - Código de Financiamento 001".

\section{CONSENTIMENTO DE USO DE IMAGEM}

Não se aplica.

\section{APROVAÇÃO DE COMITÊ DE ÉTICA EM PESQUISA \\ Não se aplica.}

\section{CONFLITO DE INTERESSES}

Não se aplica.

\section{LICENÇA DE USO}

Os Direitos Autorais para artigos publicados neste periódico são do autor, com direitos de primeira publicação para a Revista. Em virtude de aparecerem nesta Revista de acesso público, os artigos são de uso gratuito, com atribuições próprias, em aplicações educacionais, de exercício profissional e para gestão pública. A Revista adotou a licença Creative Commons Atribuição 4.0 Internacional - CC BY NC ND. Esta licença permite acessar, baixar (download), copiar, imprimir, compartilhar, reutilizar e distribuir os artigos desde que com a citação da fonte, atribuindo os devidos créditos de autoria. Nesses casos, nenhuma permissão é necessária por parte dos autores ou dos editores. Autores têm autorização para assumir contratos adicionais separadamente, para distribuição não-exclusiva da versão do trabalho publicada nesta revista (ex.: publicar em repositório institucional ou um capítulo de livro).

\section{PUBLISHER}

Universidade Federal de Santa Catarina. Curso de Ciências Contábeis e Programa de Pós-graduação em Contabilidade. Publicação no Portal de Periódicos UFSC. As ideias expressadas neste artigo são de responsabilidade de seus autores, não representando, necessariamente, a opinião dos editores ou da universidade.

\section{EDITORES}

Carlos Eduardo Facin Lavarda e Suliani Rover

\section{HISTÓRICO}

Recebido em: 08/09/2020 - Revisado por pares em: 08/02/2021 - Reformulado em: 20/03/2021 Recomendado para publicação em: 07/05/2021 - Publicado em: 30/06/2021

*Uma versão preprint do artigo foi apresentado no XXIII SEMEAD, 2020. 